\title{
III. Comparison of the findings of the two studies
}

\author{
ROBERT C. ANGELL and J. DAVID SINGER \\ The University of Michigan
}

Though we have presented here two separate and independent studies, it should be evident that they were not conducted in complete isolation from one another. Rather, the intent was to make them complementary enough to permit some tentative examination of the connection between the social values held by a nation's elites and the sort of foreign policy which that nation pursues. Our working assumption was that, while those who make and articulate foreign policy are not necessarily recruited from all of the various elite groups in a modern society, they will nevertheless tend to come essentially from the same social background as the others do. Though some appreciable deviations from this pattern might be expected in newly independent nations or in revolutionary regimes, we would not expect them in two such societies as the US and the USSR. Thus it seems reasonable to expect that the social values of the policy-makers should have a great deal in common with those of the other elites. When we move, however, from social values about internal matters to those specifically relevant to foreign policy, certain differences may well be expected, and they do in fact occur.

Perhaps more interesting in a study such as this is the question of how such general social values find expression in specific foreign policy attitudes. That we could not expect to infer such focused attitudes directly from diffuse value clusters is evident; too many other considerations intervene, requiring the adaptation of social preferences to political necessity. Thus deviations from the direct inferential line between elite values and foreign policy attitudes should be expected. On the other hand, these deviations should be minimized either as the value dimensions become more specific or as the foreign policy attitude dimension becomes more general. Since this is in fact the case in our two studies, it seems reasonable to expect an appreciable congruence between the two sets of findings.

Before turning to a summary of such congruence, and deviations therefrom, two caveats are in order. As we have already emphasized, certain distortions are inevitable in the path between either values or attitudes and their alleged expression in the media. In all societies-especially those as deeply involved in conflict as the US and the USSR were in the 1957-1960 periodelite articulations must serve many purposes. They must conceal certain domestic cleavages and exploit others, they must mobilize the society and reinforce loyalties, they must inform some segments of the 
public and confuse others, they must threaten some foreign societies and reassure others. That is, many value and attitude articulations, even if not particularly concrete and specific, are made with the conscious intent to influence the recipient. Of course, one of the purposes of content analysis is to reduce or eliminate the distorting effect of such deliberately misleading statements; the more carefully and knowledgeably designed one's dimension construction and coding rules are, the more likely the study is to penetrate or circumvent the simplifications and falsifications which are thrown up. Though we have given careful attention to the relationship which exists between our many articulating elites and their diverse audiences, and have considered in a most skeptical fashion the various purposes of their communications, there is no satisfactory way of fully validating our results and procedures. A variety of techniques in a variety of other contexts must be used, and their results compared. What we have done, however, is to tap in on many of the communication channels between these elites and their domestic and foreign audiences and, by systematic observation, we have sought to identify the major strands of their value preferences and their foreign policy attitudes.

Secondly, it should be emphasized that, even if we have captured these values and attitudes with some accuracy, the results must not be taken too literally as predictors of domestic or foreign policy. It is well established that all such ideological phenomena merely serve as guidelines to policy behavior. Even though we believe that we are tapping the operational, rather than the formal and official, end of the ideological spectrum, it must be emphasized that the relative importance of discrete values and attitudes can only be known when painful choices between conflicting demands have been made. When a foreign policy elite expresses a strong commitment to the military doctrine of retaliation-only, for example, it may nevertheless be under powerful pressure to violate the doctrine if the opportunity for quick victory presents itself or if the adversary gives evidence of grasping such an opportunity for himself. Or when an elite appears to be firmly committed to free and unfettered international trade, it may still utilize boycotts, embargoes, and export quotas when political necessity appears to override economic values. Despite the most clear and unequivocal articulations, values and attitudes can only be fully observed and measured when they are tested in the crucible of conflicting preferences and difficult choices.

Returning, then, to a summary of the congruities and incongruities found between social values and foreign policy attitudes in the two societies, let us compare some of the results which emerged. We will focus primarily on those values bearing on external relations and compare them with the related dimensions in the foreign policy attitude study. Bearing in mind the complex and circular relationship between these two sets of social phenomena, we will normally want to ask whether the relationship is best understood as: (a) values influencing policy attitudes; (b) policy imperatives influencing values; or (c) adversary's values influencing attitudes.

Looking first at the value dimension entitled Political and Military Relations to Other Nations in the Bloc, we find that it is logically connected with only one of the foreign policy dimensions-the basis and motivation for alliances (B-5). The connection seems to be of the second type for the United States. That is, the US elites tend to take the position that a good bloc is one 
in which there is national autonomy beyond the obligations imposed by specific commitments. They also see their alliances as mainly resulting from a need for protection from aggression. One can argue that the need for security produced the Western bloc, and that it then appeared to be the right kind of bloc. The Soviet elites, on the other hand, believe in a monolithic bloc; and they see their alliances as largely springing from the similarity of the nations' social systems and beliefs. There seems to be no causal connection here in either direction. The value preference is undoubtedly a fact. But to say that the reason for tight alliances is the similarity of the national systems involved is contrary to all historical experience. It appears to be a pure rationalization.

One of the cases in which values should underlie foreign policy attitudes involves the dimension Relations to Uncommitted Nations and the motivation for giving economic and technical assistance (D-9). Here we encounter seeming contradictions on both sides. American elites say either that uncommitted nations should be left to decide their own destinies or that they should be persuaded to throw in their lot with the United States. But they admit that the main reasons for economic and technical aid are to strengthen the United States side of the Cold War, or at least to keep uncommitted countries neutral. On the level of policy US elites appear to be more frank than in their stated value preferences. The Soviet elites show an opposite contradiction. They usually see the ideal situation to be revolutionary movements in the uncommitted countries that will bring them into the Communist camp, but the reason for economic and technical assistance is rarely seen as the strengthening of the Soviet side. Here the value statement seems to be more frank than the foreign policy attitude. These results possibly reflect a difference between the US and the USSR in their view of history. The latter believes that history is working with it and therefore that revolutionary movements do not have to be "bribed" through aid programs. The United States elites perhaps feel that they are working against a tide which makes impossible the carrying out in practice of values they theoretically cherish.

In this instance we have data not only on the elites' own value position but their perception of the other country's value position. The most direct evidence is dimension C-7. Here both sides state that the opponents are using economic and technical aid in order to strengthen their bloc and weaken the other. Much the same belief is revealed in $\mathrm{C}-1$, where one-quarter to one-third of the items on each side stand for a belief that the other is out to dominate the world.

The value dimension Trade with Members of the Other Bloc is comparable with the foreign policy attitude on free international trade (D-10). Because American value data were sparse and diffuse, no comparison on this side is possible. The Soviet data are highly consistent. Soviet elites believe in freely trading with the Western bloc and almost unanimously take the position that it can pave the way for a political settlement or at least tension reduction.

Degree of Trust toward Members of the Other Bloc is a value dimension that is very similar to A-1, the dimension of foreign policy having to do with the character of international politics. It should be recalled that American elites, especially the military, saw a trustful attitude as less desirable than did the Soviet elites. Consistently, the American perception of the international 
situation was one of more persistent conflict.

One would expect that the same difference would be recorded in connection with the necessary relations between states of differing sociopolitical characteristics (A-4). Oddly enough it does not appear. Neither side gives much credence to the proposition that the countries must clash militarily. It is possible that, though the American decision-makers thought of persistent conflict as most likely, they believed the US deterrent power great enough to make armed conflict unlikely.

The findings on each side's operational code are fairly consistent with the expressed value positions. The Soviet foreign policy attitudes in dimensions D-5 and D-6, having to do with whether political settlement must precede disarmament and whether controls must be imposed first, show their elite as articulating a more trusting position than that of the American elite. On the other hand, the Soviet data are very inconsistent. Despite the frequent expression of a preference for trusting the Western bloc, 24 percent of the data in C-1 indicate that they think the United States is aiming to dominate the world. And, though data are few in C-5, what few there are indicate a belief that the US would not hesitate to strike first with nuclear weapons. The American data are somewhat more consistent. Since US elites do not value trust as frequently, their strong belief that the adversary wants to dominate the world and includes the preventive or preemptive strike in its strategic doctrine is more understandable.

The value dimension War as a Means of National Policy can also be related to a good many of the foreign policy attitudes. We shall confine our treatment to those in which the relation seems most compelling.
Both sides were found almost unanimously at the position that only a defensive war is justified. The data on dimension $A-4$ are consistent with this, since they show little belief that the two sides must inevitably clash militarily. The Soviet belief that the power balance was shifting in their direction (A-7) was perfectly consistent with their value position. Since, however, onethird of the items on the American side showed a belief that the balance was shifting in favor of the Soviet Union, one may wonder whether the American consensus on a preference for only defensive war represents the true belief for that period.

Three of the items in the B group seem logically related to the value dimension War as a Means of National Policy, but it is not clear which way the causation runs. On B-1, both sides are strongly of the opinion that they are invulnerable to a surprise first strike. Both sides also believe that they can deter the other (B-2). Did they achieve these abilities because they did not want to fight unless attacked, or have they reached the value preference as a result of the attainment of these abilities? Dimension B-10 has to do with whether a nuclear war would be worth winning. The United States attitudes are very pessimistic, the Soviet elites: only a little less so. These views are almost certainly causal to the preference for a defensive posture rather than results of it.

Three dimensions (C-1, C-3, and C-5) allow us to see whether either society's position on War as a Means of National Policy is judged by the opponents to be what the elites claim it to be. As would be expected, there is a notable lack of fit. Whereas both sets of elites claim that they would not fight a war of aggression, the belief of the opponent is that they are more belligerent than this; 24 percent of the relevant Soviet items say that world domination is the prin- 
cipal goal of American foreign policy, 59 percent say that the major instrument of American foreign policy is direct military force, and 100 percent say that a preventive or preemptive strike is part of American military doctrine. The corresponding figures for American items commenting on Soviet policy are 31 percent, 28 percent, and 90 percent. If the alleged value positions are true ones, then there is a great deal of misperception.

It will be recalled that the dimension The Way to World Order showed that the Soviet elites followed the coexistence line very closely. The American elites divided their preferences between this position and one that saw order resulting from value convergence that would make international law effective. There are two dimensions, B-9 and D-3, that can be related to this value dimension. The two are very different, one having to do with how each expects to prevail over the other and the second having to do with how peace can best be maintained. The Soviet attitudes can be squared with the coexistence value without much difficulty. They expect to win by their own strengths and American weaknesses; and only 18 percent of the items state that peace can best be maintained by Soviet military power. Nor is there any necessary inconsistency in the fact that Americans expect to win the Cold War almost entirely through Soviet weaknesses. But it is hard to square the frequently expressed preference for value convergence with the fact that almost half the American items state that peace can best be maintained through American military power.

Finally, the dimension Relation to International Agencies can be compared both with the dimension just discussed (D-3) and to D-7, which has to do with political decision-making in the United Nations. On the Soviet side the results are fairly consistent. Their elites were less enthusiastic in their evaluation of the United Nations than were the American elites and that organization was not cited as often in their foreign policy materials as the best instrument to maintain peace. Similarly, the Soviet foreign policy items inclined more to insist upon great-power unanimity in the United Nations than did those on the American side. This insistence on the veto indicates considerable distrust of the United Nations as it was then constituted.

We have found, then, what could have been anticipated, that there are three levels here: (1) what nations do in international relations; (2) what their decision-makers say their foreign policies are; and (3) what members of elites say their value preferences are.

In conclusion, our hope in this enterprise was to build a somewhat more solid empirical base for the study of foreign policies than has hitherto been available. That is, we sought not so much to describe and analyze the policies of these two societies as to expose some of the ideological and attitudinal factors which might predict to these policies. Bearing in mind the distinction between actual behavior and verbalization about it, we can only hope that we have illuminated some of the linkages between elite values and attitudes on the one hand and foreign policy on the other. Two further studies would seem to be suggested by those presented here, if their validity and utility are to be ascertained. In one, it might be quite valuable to assemble a panel of perhaps ten independent judges, and then provide them with three sets of materials: (a) the finished report on value preferences embodied in Part I; (b) a formulation of our model relating elite values to foreign policy operational codes; and (c) a blank 
form of the foreign policy attitudes report found in Part II. The task would be to see how accurately our value data and model would predict to the foreign policy attitude results. Of course, failure to replicate our findings could, with more or less equal probability, be attributed to inadequacies in the value data, the model, the attitude data, or-unfortunately-the judges. Equally interesting, but more difficult, might be an effort to: (a) sample and then code the foreign policy behaviors of the two powers during, or perhaps after, the period studied; (b) on the basis of our findings in the pres- ent study, predict independently what these behaviors should have been; and (c) compare the results. Again, low correlations may not necessarily be attributable to any one of the given sets of data, but such an effort to move back and forth between articulation and overt action could be a challenging enterprise indeed. The foreign policies of the major powers are relevant enough to man's survival today to warrant a considerably more empirical and rigorous approach than that hitherto utilized. We hope that this is a small step in that direction. 